\title{
The Long Hello: Energy Governance, Public Participation, and 'Fracking'
}

\author{
Dr John Whitton and Dr Ioan Charnley-Parry
}

Lancashire Institute of Citizenship, Society and Change and Energy and Society Research Group, University of Central Lancashire, Preston. Lancashire. UK. PR1 2HE

\subsection{Introduction}

In this chapter, we discuss the promotion of shale gas as a part of a UK energy mix of renewable, fossil fuel and nuclear technologies. This seems to go against international agreements signed by the UK Government and others to reduce global greenhouse gas emissions. We frame our discussion in terms of 'Energy Governance' and our own conceptualisation of social sustainability. Whereas the decline of fossil fuels has elicited the title of this book as the 'Long Goodbye', our experience in England, UK has been of rather an emerging interest in and extended 'Hello' to shale gas and the process of unconventional gas recovery-hydraulic fracturing or 'fracking'. Shale gas exploration has the potential to enhance national energy resources and therefore energy security, whilst lowering energy prices and providing a 'cleaner' alternative to coal exploitation, whilst conversely having the potential to degrade and contaminate the environment through industrial activity and waste water leakage and induce seismic activity (Sovacool, 2014). Hence the impacts of activities associated with hydraulic fracturing and the broad societal benefits of shale gas are contentious and contested.

In Lancashire, UK the planning process has so far taken around 8 years. In terms of research positionality, we write as academics of a University based in Preston, Lancashire, in what the Conservative Peer Lord Howell (UK Energy Secretary from 1979 to 1981), memorably referred to in a speech to the House of Lords in 2013 as a "desolate area" of the UK (Stacey and Pickard, 2013) - since termed 'the desolate North' - a comparison difficult to make with the range of National Parks, Areas of Outstanding National Beauty and Sites of Special Scientific Interest. We have experienced peaceful protest and road blocks at Preston New Road (near Blackpool), protest outside Preston Town Hall as councillors meet to make planning decisions and industry lobbying in the shale gas county. In October 2018, hydraulic fracturing was carried out in the village of Little Plumpton, Lancashire for the first time since the process was linked to earthquakes in the same area in 2011. This, despite local councillors rejecting the application for shale gas exploration. This activity has again coincided with a series of low magnitude earth tremors that have caused work at the site to cease for short periods of time. The events have been reported widely in the media, generating local and national debate around the environmental implications of hydraulic fracturing.

One of the main findings from our ongoing research is the frequency in which the same or similar issues are raised in public forums relating to energy governance, social justice in decision making and citizen participation, irrespective of the energy source under discussion. We discuss these issues below and present our framework for social sustainability as a tool to enable researchers and communities alike to tackle some of these issues in the context of ongoing energy transitions and their impacts on society. Underpinning our discussion is the assertion that whilst understanding the social dimensions and implications of energy transitions is important, at present it is understudied and insufficiently understood. In order to progress, a deeper understanding of the social implications of energy infrastructural developments in general must be sought (Miller, Iles \& Jones, 2013), whereby the complexity of 'societal impacts' is further explored. We argue that deliberative engagement with public stakeholders, local communities and societal groups that are likely to be impacted by energy system change 
plays a central role in enhancing our understanding of energy transition impacts and impact management itself.

\subsection{Energy Governance and Shale Gas}

Energy Governance fundamentally links the problem of anthropogenic climate change and energy transitions associated with decarbonising the economy. New governance structures are required to manage such transitions and their direct consequences - not only for national energy policy institutions and energy industries but for communities that rely on fossil fuel exploration for employment, economic development, regeneration and services. However, running in parallel to the low carbon energy transition is the additional disruption of shale gas and tight oil; seen either as a "new era of energy abundance" by observers such as Rex Tillerson the Chairman and CEO of ExxonMobil (Tillerson, 2013), or as a sign that we are entering the "Era of extreme energy" (Klare, 2011). Although a complex, multifarious notion, we consider governance in the context of public participation and social justice, contributing to the evolving research on energy justice (Bickerstaff, Walker \& Bulkeley, 2013; Sovacool \& Cooper, 2013; Sovacool \& Dworkin, 2014; Sovacool, Sidorstov \& Jones, 2014). Evaluating where injustices occur within this context and what processes exist to remedy these (Jenkins et al., 2016) would seem a sensible definition of our approach to understanding energy justice. We consider how energy systems can or should be governed in a way that contributes towards a fair and just society.

Clearly, for governance to be effective, culture, socio-economics and trust play a role if outcomes are to be considered fair and equitable, particularly in a democracy where citizens expect to participate in influencing government energy decision making or for decisions to reflect their concerns. Beierle (2002) states that fairness in participation is achieved by broad representation and equalisation of participants' power, whilst competence often involves the use of scientific information and technical analysis to settle factual claims. Other authors have disputed this equalisation of participants' power as an ideal not always represented in deliberative practice. van Stokkom (2005) emphasises that deliberative processes to inform policy do not always meet equality and rationality ideals. Behind the ideal of rational dialogue between equal participants the author finds an interplay of power and emotion dynamics that can aid or impede deliberation. Whilst procedural fairness is important, it is also the fairness of outcomes and how they are distributed that truly matters to those impacted by large-scale and/or contentious energy developments and has also been shown to influence societal acceptance (Visschers \& Siegrist, 2012). Despite the significance of technological considerations and challenges, the process of unconventional oil and gas exploration is clearly not simply a technological issue (Centner, 2016). We acknowledge that energy-related technological solutions to mitigate against climate change are being seen as a priority due to concerns relating to the sufficient timeliness and extent of societal and economic change (Lee et al., 2012).

In 2014, then UK Prime Minister, David Cameron declared the government was "going all out for shale", announcing that cash strapped local authorities would benefit from business rates raised from shale gas sites (Watt, 2014). In the same year, then US President Barak Obama in his State of the Union address publicised natural gas as a transition 'bridge fuel', extolling the virtues of natural gas as a low carbon alternative to coal (Plumer, 2014). Democrats in the US, influenced by Bernie Saunders, later changed their view, incentivising wind and solar power over natural gas (Lin, 2016). The oil and gas industry clearly have hopes beyond transition, hoping that natural gas will play a large role in future energy supply in addition to the development of renewable energy (Bousso, 2018). The UK Government is encouraging shale gas exploration and considers the fuel to be part of a UK energy mix with nuclear and 
renewables. Either way, the development and extraction of unconventional energy resources from shales, coal beds and tight sands, has become one of the most important global energy policy phenomena of the $21^{\text {st }}$ century (Whitton et al., 2018b), which has increased the global supply of hydrocarbons and lowered their price (Van de Graaf, 2017). However, the plentiful supply and demand for hydrocarbons is in stark contrast to international agreements to reduce greenhouse gas emissions, such as the Paris Agreement that came into force on 4 November 2016. At the time of writing, 55 Parties were signed up to the Convention, representing around $55 \%$ of total global greenhouse gas (GHG) emissions. Despite signatories agreeing to accelerate and intensify the work needed for a sustainable low carbon future, a substantial effort - over and above that agreed - is now required if there is any chance of meeting the target of keeping global warming below 2 degrees Celsius (Rogelj et al., 2016). This and the assertion in October 2018 by the Intergovernmental Panel on Climate Change (IPCC) that limiting global warming to $1.5^{\circ} \mathrm{C}$ compared to $2^{\circ} \mathrm{C}$ could go hand in hand with ensuring a more sustainable and equitable society (IPCC, 2018). The report makes it clear that we are already experiencing the adverse effects of $1^{\circ} \mathrm{C}$ of global warming.

Debates persist on the role of shale gas within a modern energy landscape. Weijermars et al. (2011:402) assert that until renewable energy technologies mature and are able to produce large quantities of energy to meet demand in an economic manner, gas production from unconventional resources must continue to "bridge the transition period". In addition, unconventional gas is considered to hold the potential to reduce dependency on imports, thus enhancing energy security whilst building resilience against "price shocks and supply interruptions" (Weijermars et al., 2011: 404). The notion of time is worth noting here; a factor that is of central importance in both the climate change and energy transitions debates. Time (as one factor among several) is seen as necessary for renewable technologies to develop and 'mature', but conversely time is an ever-decreasing resource and has a direct impact on whether international emissions reduction targets are to be met or if efforts to prevent a global temperature rise of above $1.5^{\circ} \mathrm{C}$ (IPCC, 2018) are to be effective in stemming climatic volatility. A conflict exists; time must be allowed for a broad range of renewables (i.e. beyond the notably maturing technologies of solar and onshore wind) to develop and contribute to reducing energyrelated emissions, whilst the forecasted window of time in which action against long-term climate mitigation is reducing rapidly. We discuss this later in the chapter. Another important factor in the energy governance narrative is that of societal influence or 'participation', which we discuss below.

\subsection{Participation}

There is increasing acknowledgement that public support for energy technologies is not entirely based upon the assumption of public trust in technical expertise and the assurances of developers. We see this theme in our work on energy governance (Whitton et al., 2018a) and that of other authors, such as Anna Szolucha in Lancashire UK and Grabowiec, Poland (Szolucha, 2018), Imogen Rattle, James Van Alstine and Tudor Baker in Lancashire and Yorkshire, UK (Rattle, 2018). These authors highlight the public experience of a system of governance, perceived by residents to favour development over their concerns - based on recent events in Lancashire, UK it would seem their concerns are well founded. Conversely, there also exists a degree of long-standing mistrust of 'the public' in the context of "high level policy discourse" around the significant technological transitions and transformations required to mitigate severe climate change (Lee et al., 2012:33). The uncertainty surrounding the impact on local communities, their residents and how they will influence the policy-making process surrounding shale gas has been identified to have produced barriers to the 'pro-fracking' government policy in the UK (Cairney, Fischer \& Ingold, 2015). This has also been the case 
for wind turbine developments in Ontario, Canada (Christidis, Lewis \& Bigelow, 2017), where the authors find that changes to policy and decision-making processes may address opposition.

Public engagement upstream of the decision point for siting controversial technologies is widely discussed (Corner, Pidgeon \& Parkhill, 2012; Wilsdon \& Willis, 2004), whereby heterogeneous publics are provided access and resources to engage in processes, by which they may form adequate personal opinions and preferences through informed deliberation and public debate on issues that may affect them. This is increasingly seen as a benchmark for dealing with technology-generated social controversy (Felt \& Fochler, 2008; Flynn, Bellaby \& Ricci, 2011; Hagendijk \& Kallerud, 2003). The concern voiced by these authors, and echoed here, is that there needs to be adequate public engagement in the processes of assessing both the social and ethical feasibility of shale gas as a fuel and a technological solution to energy security, climate change and economic growth (a participatory technology assessment process), and for siting new shale gas installations downstream at the point of siting actual fracking wells. If this is absent, then decision-making will reflect the choices of central, institutional actors rather than those that are directly affected (Kleinman, 2000). By looking across the case studies of other energy technology siting processes, it is clear that to do so would likely lead to public opposition, political controversy and eventual planning failure. The uncertainty of how local communities and impacted residents will influence the policy-making process surrounding shale gas has been identified by some to have produced barriers to the pro-fracking government policy in the UK transforming into a pro-fracking policy outcome (Cairney et al., 2015). Beyond shale gas, scholars such as Lee et al. (2012) observe that despite legal obligations in national, EU and international law to provide opportunities for public participation during consenting processes for nationally significant energy projects, strategic planning policy appears to offer up very little of significance to be discussed and that can be legitimately influenced. The potential for participation to become a frustrating "bureaucratic hurdle" (Lee et al., 2012: 33) for stakeholders, whereby legal rights to participate only bear limited opportunities to legitimately influence process (Lee et al., 2012) is an important consideration in the energy transition debate. It is of particular significance given the degree of technological change that is likely required to mitigate climate change.

We have highlighted the US regulatory systems' complexity, heterogeneity, lack of transparency, and limited local voice for US stakeholders previously, whereas we have discussed how in the UK the concept of public engagement has become an institutionalised facet of energy technology development processes (Whitton et al., 2017). However, numerous national case studies point to institutional failures to site controversial energy-related technologies in the absence of sufficient community-level participation in the planning process. So, where and how can the public engage on issues relating to shale gas developments?

\subsection{Incorporating Social Justice into Energy Infrastructure Decision Making}

Energy transitions represent a myriad of transformational shifts within an energy system, which inevitably - directly and indirectly - impact upon societies via changes not only to technologies and the price of energy itself but to the "broader social and economic assemblages" associated with the production and consumption of energy (Miller et al., 2013: 135). Energy system change involves the social process, changes and outcomes that may go unnoticed by more analytical approaches. As part of such transformations, decision-making is complex and reactive to changing circumstances and pressures on that system. However, towards the implications of these multi-scalar transformations, energy debates are considered by some to be limited in scope, insufficiently informed, and 'stunted', whereby they underemphasise how and to what degree energy systems impact upon societies whilst little opportunity for societal 
involvement and influence is available, beyond that of traditional technocratic actors such as engineers and bureaucrats (Miller et al., 2013).

As early as 2007, researchers highlighted that social acceptance was and would continue to be a constraining factor in achieving ambitious government target for the deployment of renewable energy technologies in numerous countries (Wüstenhagen, Wolsink \& Bürer, 2007). The authors highlight wind energy as particularly problematic because of visual impact on landscapes. This has indeed proved to be the case - at the time of writing Dumfries and Galloway local councillors formally objected to a 30-turbine wind farm development near Wanlockhead in the Lowther Hills. The decision will now rest with the Scottish Government. The same authors also highlight how the influences on socio-political and community acceptance are increasingly recognised as being important for understanding the contradictions between widespread support for renewable energy and the public objection to projects. The planning process relating to nationally significant infrastructure projects (NSIPs) has also been the subject of recent academic research by academics at UCL. The UK Research Council study focuses on decision making and participation on large renewable energy developments, (UCL, 2017). Previous work conducted by the same authors (Rydin, Lee \& Lock, 2015) suggests a strong policy commitment by Government to promoting low carbon energy infrastructure and implies a prior 'in principle' assumption that the proposed development is necessary. Interesting for our work here, is that the authors raise a concern regarding the legitimacy of a process that provides legal provision for citizens to participate, but in a context that may restrict the potential for public concerns and aspirations to influence final regulatory decisions.

We argue that a seldom-considered element of energy transition decision-making is that of fairness - that is socially sustainable decision making. If these decisions are deemed to be unfair by society, they may be perceived as 'unacceptable', face challenge or objection, and potentially fail to achieve broad social acceptance. Social justice, whereby the multifarious impacts on communities (also conceived of as end users, customers, 'the public') are understood, acknowledged and influence process, must play a visible role in energy-related decision-making, particularly when this involves significant 'transition-level' planning and change and if decisions are to be achieve any degree of societal support or acceptance. We have discussed previously in a comparison between the UK and US, how existing systems of energy governance provide insufficient opportunities for substantive engagement (Whitton et al., 2017). According to Thibaut and Walker (1975), it is the belief of citizens that procedures hold importance, because "fair procedures produce fair outcomes" (MacCoun, 2005: 182). However, these produce multiple and often unknown outcomes and impacts upon societies, raising concerns surrounding social justice, notions of 'procedural fairness' and 'procedural justice' of the decision-making processes. For project developers, meeting procedural justice ideals with transparent decision making is an important factor in avoiding conflict with local populations (Gross, 2007). In this sense, demonstrable justice and fairness during processes such as participation and decision-making can aid in increasing local support for a project. Where acceptance is not achieved, local opposition often exists, which is economically and socially costly to both developers and communities as it can result in planning delays and a loss of trust (Cotton \& Devine-Wright, 2011), of which the latter is notably difficult to retrieve. Rootes (2006) has also shown how the absence of procedural justice can reveal how power relations between local actors may be imbalanced, which has ethical implications for decisionmaking policy making surrounding nationally significant infrastructure projects (NSIPs). We argue that the absence of demonstrable social justice within shale gas projects will likely lead to societal resistance and opposition, political critique, and the inability to be deemed as positive or 'good'. 
As Lebel et al. (2006) state, the central goal of good governance is social justice, whereas Fung (2015) describes social justice as a central value of democratic governance. In short, effective governance requires social justice at its core, and we argue that effective governance is required to achieve any sense of energy justice in relation to shale gas projects. As part of this effective governance, participation that is legally required must also take the form of legitimate engagement with opportunity for deliberative dialogue and for this engagement to result in genuine procedural influence. We wish to avoid the scenario forecasted by Lee et al. (2012), whereby affected communities may grow frustrated and become disillusioned with engagement processes due to their perceived superficial and bureaucratic nature. Rather, we would employ an approach focussed on moving beyond consultation to deliberation and debate, knowledge and experience sharing, learning, and the envisioning of desirable futures. We also respond to the calls of other scholars for improvements to infrastructure-related decision-making through the guarantee of "social contribution" and improvements in public methodologies to "best represent social needs" (Sierra et al., 2018: 510), thereby increasing decision-making legitimacy and efficacy in the view of public stakeholders. This represents a move towards more socially informed and just energy decisionmaking as part of effective energy governance.

In the UK, a small number of exploration companies dominate shale gas exploration, one of which is Cuadrilla. Cotton, Rattle and Van Alstine (2014) discuss procedural justice in the context of Cuadrilla's shale gas exploration activities in Lancashire, UK in recent years, concerning community benefit practices and community engagement with locally affected communities. Permitted site licenses which were obtained prior to Cuadrilla's exploration activities did not require Environmental Impact Assessments (EIAs). Due to these activities being exploratory as opposed to commercial, and being declared to cover an area under 1 hectare (Kotsakis, 2012), Cuadrilla's practices complied with the legal regulatory framework (Town and Country Planning Regulations 1999 in England and Wales), but were questionable in regards to their social acceptability. Cotton et al. (2014: 433) observe that by avoiding the EIA, the company's practices avoided generating a social licence to operate (SLO), failing to produce any degree of "ongoing status of local stakeholder approval". Howard-Grenville et al. (2008) highlight the importance of SLO due to the unintended consequences for industry, such as conflict, opposition and project delays, that may arise by ignoring or acting contrary to the expectations of local publics. There can also be regulatory consequences if regulatory authorities experience pressure from elected representatives to bridge this social gap and tighten regulatory conditions (Gunningham, Kagan \& Thornton, 2004). As this agreement with communities is not a legal requirement and is intangible, companies and industries may question its value or impact; however, Calvano (2007) has shown that communities surrounding these developments can become sites of social conflict and political contestation. Cotton et al. (2014) note that gaining SLO requires establishing procedural fairness, by engaging communities in decision-making over site licensing, an observation also made by Gross (2007). However, the authors propose that Cuadrilla's communication with communities in Lancashire and Suffolk were insufficiently deliberative, and merely demonstrated 'deliberative speak' (Hindmarsh \& Matthews, 2008), communicative rhetoric which fails to ensure that communities are involved in decision-making and establish a SLO.

Recent proposals look to provide local authorities in the UK with monetary incentives, such as $100 \%$ business rates for extraction activities, which carry potentially negative implications for the impartiality of these bodies and may damage "the procedural environmental justice capabilities for councils to protect vulnerable constituents" (Cotton et al., 2014: 434). At the present time, the recently re-formed Conservative government launched a consultation document on the Shale Wealth Fund (SWF) (see Treasury, 2016), which provides details on how additional revenue could be provided to local communities, to 
populations affected by shale gas development sites, beyond funding provided by the shale gas industry (UKOOG, 2016). Funding, incentives and community benefit packages are reported elsewhere as becoming a common characteristic of site selection strategies for other energy industries, such as nuclear, or more specifically nuclear waste management (see Kojo \& Richardson, 2014). On the subject of revenues derived from shale gas developments, US-based research conducted by Paydar et al. (2016) explores the association between local public support for unconventional gas development (UGD) (Boudet et al., 2014) and UGD-related public revenues disbursed to county and municipal governments. The authors find a positive correlation between the collection of 'impact fee' revenues and support for UGD projects, and importantly, that higher rates of public support were found to be associated with municipallevel payments than to county-level governments. Such findings have governance implications for the UK, in that it may be more socially acceptable and supported for revenue-based support to 'shale gas communities' to be managed at a more decentralised, local scale, where communities and local institutions have greater influence on how development-related funds are distributed and utilised in their locality.

The notion of locality holds relevance in discussions and decisions around shale gas exploration. Communities that are geographically distant from shale gas sites, and therefore not deemed to be 'associated' or 'local' to shale gas sites but are perceived by some to be 'impacted' by shale gas operations (e.g. by the transport of development-related resources and materials by heavy goods vehicles through or close to these communities) may suffer from this locally-targeted economic governance of 'shale gas benefits'. This has implications for the distributive justice of benefits provision from such developments. Whilst important, participation in decision-making is not enough for 'a just system' to be realised; justice requires both process and distributive aspects to be addressed and fulfilled. In a recent study by Cotton (2016), the author applies an ethical framework for policy evaluation of shale gas in the UK, based on the work of Kristin Shrader-Frechette (Shrader-Frechette, 2002) which considers the interrelationship between the distributive and procedural elements of environmental justice. In applying this framework, Cotton emphasises the argument that government and industry organisations must address both procedural and distributional justice challenges to demonstrate that the decision-making process and outcomes respectively of such developments are ethically legitimate. He also argues that fracking-related planning policy development links to deeper problems of participative and consent-related injustice that relate to ongoing processes of planning reform (the Planning Act 2008, the Localism Act 2011 and now the Infrastructure Act 2015) that shorten decision times across multiple planning consent regimes and remove powers from local communities for decision-making control by rescaling decisions from local to national scales. We contend that this has broader energy justice implications on the shale gas industry and its activities. This highlights again the critical role that time plays in energy-related processes, albeit in a participatory and justice context. We have previously noted the timebased conflict that exists between renewable technology development and climate changerelated action. Not only is the diminishing window to act to prevent global temperatures surpassing an increase of $1.5^{\circ} \mathrm{C}$ creating a barrier to allow for renewable technological maturity, but those same time constraints appear to be contributing to the implementation of policies with limited opportunities for legitimate societal engagement and genuine participation in decision-making. In this sense, the issue of impending climatic changes act both as a driver for the development of lower-carbon energy sources and a barrier to the capacity of decisionmaking processes for societal involvement and influence. Indeed, time serves as both a predicament for climate-related resolution and for democracy.

How do we respond to what we have identified thus far, and what do we propose in address of such observations? In the context of enhancing governance procedures, we propose that a systemic, participatory, community-led approach is required to achieve any sense of how 
participation that is procedurally just and fair can be defined, in a community setting and within the context of energy developments. Such an approach incorporates multi-directional dialogue, where local stakeholders are viewed as assets to utilise to improve and legitimise decision outcomes. This in turn contributes towards procedural justice as experienced by affected communities as stakeholders, and more broadly towards the energy justice exhibited by technologically-based development. This is also facilitated by a move away from the technocratic D-A-D approach (Decide Announce Defend) toward the more democratic and collaborative E-D-D approach (Engage Deliberate Decide) of governance and decisionmaking. Whitton et al. (2015) have previously proposed this type of approach with the aim of achieving a form of legitimacy that allows communities to derive social priorities through 'community visioning'. Community visioning is a process that enables differing viewpoints to be understood through dialogue. Local people come together to identify and debate community values, to highlight both current issues and future opportunities, and then co-develop plans to achieve an agreed vision (Ames, 1997, 2006; Cuthill, 2004). This approach promotes several critical elements, useful within the context of shale gas developments. The first is democracy in shale gas decisions; the manifestation of this being public involvement in energy decisions as part of the dialogue between government, industry and local communities. The second is that the process itself is evidence of a form of procedural justice in shale gas decisions that advances a concept of fairness. In this respect the question asked should be; 'is the process perceived as fair, and is the outcome equitable?' This concurs with the suggested necessities of ethically legitimate decision-making, in both procedural and distributive contexts, as discussed by Cotton (2016).

In terms of process, the approach is community led and asset based (using the skills and resources based in the community), using deliberation to generate community priorities. We aim to initiate a lasting change within communities through building social capital; focusing on community assets not deficits (National Council for Voluntary Organisations (NCVO), 2014). An example of this approach on a national scale is provided by Big Local Trust, the $£ 220 \mathrm{~m}, 15$-year UK National Lottery programme to encourage voluntary action and community development to support communities to achieve their own goals. This decentralised governance structure sees funds spent according to the priorities and needs of local communities, as articulated by community members, an approach which we argue can inform the development of a socially just and ethically legitimate system of governance for shale gas developments.

The notion of social justice as part of a system of energy governance is important is energy transitions are to be broadly positive and beneficial to a wide range of stakeholders and community members. As Miller et al. (2013) discuss with regard to the notion of energy justice, energy transformations must be examined in order to identify whether they will or could perpetuate existing or create new negative impacts of energy production and use and thus the ways in which this can be mitigated. Engaging with currently or potentially affected communities can assist in this endeavour to understand how energy transitions and the changes inherent in them may impact them, including whom may be particularly affected and for what reasons. As a point of definition here, Miller (2012: 48) has previously suggested that energy justice encompasses "choices about what kinds of energy systems to build for the future, where to build them, and how to distribute their benefits, costs, and risks". With this in mind it is important to seek not only traditional 'expert' views on what these benefits, costs and risks are likely or expected to be, but the perspective of those who are to be directly impacted by energy transitions and experience how these benefits, costs and risks may manifest and distribute themselves 'on the ground'. In order to ensure that the governance of energy transitions is just and fair, we must do more to understand what would be considered just and fair by those who 
will now and for many years in the future, within a myriad of different contexts and from a variety of perspectives, such does the complexity of local communities require.

\subsection{Social Sustainability}

Infrastructure-related social sustainability is a subject that scholars observe is neglected but emerging as an area of interest (Sierra, Yepes \& Pellicer, 2018). It is an area which our work seeks to contribute towards in-part due to the detrimental effects that socially under-informed and inconsiderate planning and decision-making can have on society and the project ( Sierra, Yepes \& Pellicer, 2018; also see Naderpajouh et al., 2014; Temper, del Bene \& Martinez-Alier, 2015), and on fulfilling societal needs and priorities. Engaging in social science research on the subject of hydraulic fracturing and unconventional hydrocarbons is recommended by scholars to increase our capacity to identify potential risks, impacts and implications for society, so that we may effectively assess and gauge the prudency of proceeding with shale gas exploitation (Centner, 2016). More broadly, we argue that further research is required in examining the social sustainability and social impacts of energy transitions in the UK, of which North Sea and shale gas may play a role our transition from coal and imported gas. However, there are clearly renewable alternatives. Both renewable and non-renewable energy sources face opposition to deployment; non renewables due to GHG emissions, statutory nuisance, hazards to health and difficulties with extraction and renewables due to visual impact (e.g. wind) and impacts on the natural environment (e.g. tidal barrage).

We have recommended a process whereby affected or potentially affected public stakeholders can deliberatively and openly discuss project plans and impacts in the context of local contexts (Whitton et al., 2015), and then inform and influence project-related decisionmaking processes, thus contributing to efforts to address a lack of societal inclusion and social justice. There is insufficient focus on social sustainability in the energy transitions literature, and more research must be conducted in order to identify how social sustainability is represented in different energy transition scenarios and to disparate societal groups who may be impacted. For example, social development and sustainability can often be effectively understood through the exploration of local experiences whereby local context can be discussed in nuanced detail (Karami et al., 2017; Soltani et al., 2015), as opposed to the opinions and predictions of external experts.

This approach echoes calls in the academic literature for energy debates to be "informed by robust empirical and theoretical inquiries" (Miller et al., 2013: 136) into how energy transitions will affect social groups. We argue that a crucial aspect of understanding sociotechnological systems and the changes they undergo is exploring the experiences of local communities and disparate societal groups through deliberative dialogue, thereby understanding how energy transitions may impact upon social sustainability at the local scale.

We have previously proposed a social sustainability framework for energy infrastructure decisions (Whitton et al., 2015), particularly relevant for the exploration of energy transitions and their societal impacts. Other scholars have similarly called for the development of methodologies that better assess the socio-economic impacts of expanding energy infrastructure and explicit consideration of the long-term impacts of this infrastructure on local communities and economies (e.g. renewable energy infrastructure, Rydin et al., 2018), both being areas which our approach seeks to dialogically explore. We focus on engaging in deliberative dialogue with a number of affected social groups within a locality, exploring what sustainability means to them and how sustainability is perceived, particularly in a social context. From this, sustainability criteria can be co-developed based on the group's social priorities and ranked by importance. These discussions are framed via the introduction of a particular energy technology or energy transition narrative, through which the social 
sustainability criteria are re-prioritised based on perceived social impacts. Once these criteria are prioritised in the context of social impacts, the approach then seeks to explore with each group the notion of 'desirable futures' involving these discussed technologies or transition examples. Desirable future scenarios are then co-established from these group dialogues, which are used as a basis for reflection and deliberation to establish how these desirable futures can be achieved in a socially sustainable manner. Suffice to say other dimensions of sustainability will naturally be discussed within group dialogue but that the thematic focus is that of social sustainability in an energy context. Through this approach, both local context and the diverse needs and priorities of local communities can be explored and understood within specific energy contexts, whereby findings can inform and influence specific decision-making processes.

\subsection{Conclusion}

Our discussion of energy governance and participation when considering the future of shale gas exploration or 'fracking' raises a number of issues, whilst also highlighting areas for future research. A persistent issue is that of transparency and access to planning and decision-making surrounding hydraulic fracturing in the UK and the degree of agency afforded to affected communities. After 8 years of exploration, communities such as those in Lancashire remain concerned about the environmental and social implications of this energy technology. Given recent judicial outcomes allowing fracking to go ahead, communities feel that fair governance is inconsistent with locally made decisions having been overturned by government. Recent earth tremors as a result of exploratory activity in Lancashire has furthered the debate on the environmental justice implications of shale gas exploitation in the UK.

The tension between national energy security, climate change obligations and democracy is one that underlies the shale gas debate but also other energy projects, particularly in the UK where government support nationally often contrasts with an ever-present scepticism and uncertainty among local communities and the wider population. Without adequate, legitimate and timely participation in decision-making, where pre-determined outcomes are avoided, local support for energy developments will experience ongoing stagnation.

Energy development 'without the community' is likely to engender a dearth of community support, whether national energy interests are met or not. In short, opaque and unjust processes will likely lead to unjust and contested outcomes.

In both the US and the UK we have observed a lack of opportunity for local communities to engage in dialogue to influence development outcomes for unconventional energy developments. If shale gas resources are to be explored and exploited, then the complexity, uniqueness and priorities of local communities must also be explored. Unconventional and other large-scale energy projects require more than public consultation. We argue that deliberation, open debate, and early-stage dialogue with a range of social groups is necessary for any form of effective and fair energy governance. We have proposed a framework for exploring both conceptions of local sustainability and perspectives on what a sustainable energy future could include for local communities.

The complexity of energy transition and the associated timeframe for action to meet emission targets and mitigate irreversible global temperature increases suggests that energy system changes will affect society in a myriad of ways and to varying degrees. It is due to this complexity and contentious nature of energy technologies that work is required to examine and understand the unique impact of energy transitions in specific localities. We argue that collaborating with local communities, whereby diverse local needs, experiences and expertise, and priorities are explored is more likely to lead to decisions that are socially sustainable. 
Regarding shale gas in particular, the UK Government narrative regarding its commitment to a reduction of $\mathrm{CO}_{2}$ emissions whilst promoting a shale gas industry is a confusing one. How is this compatible with a just energy transition away from traditional fossil fuels and towards 'cleaner' energy? What role, if any, will shale gas have alongside renewable energy technologies in the UK to aid climate change mitigation efforts, in the context of an ever-decreasing window of opportunity? Indeed, is time rather than technocracy the emerging primary factor in the restriction of deliberative and dialogic opportunity? These areas require further attention and research.

\section{REFERENCES}

Ames, S. 1997. A Guide to Community Visioning. Washington, D.C.: American Planning Association.

Ames, S. 2006. "Community Visioning”. In F. R. Steiner \& K. Butler (Eds.), Planning and Urban Design Standards (pp. pp. 39-40). Hoboken, NJ: John Wiley and Sons.

Beierle, T.C. 2002. The Quality of Stakeholder-Based Decisions. Risk Analysis, 22(4), 739749. doi:10.1111/0272-4332.00065

Bickerstaff, K., Walker, G. \& Bulkeley, H. 2013. Energy Justice in a Changing Climate: Social equity and low-carbon energy. London, UK: Zed Books.

Boudet, H., Clarke, C., Bugden, D., Maibach, E., Roser-Renouf, C. \& Leiserowitz, A. 2014. "Fracking" controversy and communication: Using national survey data to understand public perceptions of hydraulic fracturing. Energy Policy, 65, 57-67.

doi:10.1016/j.enpol.2013.10.017.

Bousso, R. and Nasralla, S. (2018, 09/10/2018). Natural gas here to stay beyond energy transition, Big Oil says. https://www.cnbc.com/2018/10/09/reuters-america-natural-gashere-to-stay-beyond-energy-transition-big-oil-says.html.

Cairney, P., Fischer, M. \& Ingold, K. 2015. Hydraulic fracturing policy in the UK: coalition, cooperation and opposition in the face of uncertainty. Paper presented at the Political Studies Association Annual International Conference, Sheffield, UK. https://www.psa.ac.uk/sites/default/files/conference/papers/2015/Cairney\%20Fischer\%20In gold\%20fracking\%20in\%20the\%20UK\%2025\%20Feb\%202015.pdf.

Calvano, L. 2007. Multinational Corporations and Local Communities: A Critical Analysis of Conflict. Journal of Business Ethics, 82(4), 793-805. doi:10.1007/s10551-007-9593-z.

Centner, T.J. 2016. Observations on risks, the social sciences, and unconventional hydrocarbons. Energy Research and Social Science, 20, 1-7.

Christidis, T., Lewis, G. \& Bigelow, P. 2017. Understanding support and opposition to wind turbine development in Ontario, Canada and assessing possible steps for future development. Renewable Energy, 112, 93-103. doi:https://doi.org/10.1016/j.renene.2017.05.005.

Corner, A., Pidgeon, N. \& Parkhill, K. 2012. Perceptions of geoengineering: public attitudes, stakeholder perspectives, and the challenge of 'upstream'engagement. Wiley Interdisciplinary Reviews: Climate Change, 3(5), 451-466.

Cotton, M. 2016. Fair fracking? Ethics and environmental justice in United Kingdom shale gas policy and planning. Local Environment, 1-18. doi:10.1080/13549839.2016.1186613.

Cotton, M. \& Devine-Wright, P. 2011. "NIMBYism and community consultation in electricity transmission network planning". In P. Devine-Wright (Ed.), In: Renewable energy and the public: From NIMBY to participation. London, UK: Earthscan. 
Cotton, M., Rattle, I. \& Van Alstine, J. 2014. Shale gas policy in the United Kingdom: An argumentative discourse analysis. Energy Policy, 73, 427-438.

doi:10.1016/j.enpol.2014.05.031.

Cuthill, M. 2004. Community Visioning: Facilitating Informed Citizen Participation in Local Area Planning on the Gold Coast. Urban Policy and Research, 22(4), 427-445. doi:10.1080/0811114042000296335.

Felt, U. and Fochler, M. 2008. The bottom-up meanings of the concept of public participation in science and technology. Science and Public Policy, 35(7), 489-499.

Flynn, R., Bellaby, P. and Ricci, M. 2011. The limits of upstream engagement in an emergent technology: Lay perceptions of hydrogen energy technologies. In P. Devine-Wright (Ed.), Renewable energy and the public: From NIMBY to participation (pp. 245-259). London: Routeledge.

Fung, A. 2015. Putting the Public Back into Governance: The Challenges of Citizen Participation and Its Future. Public Administration Review, 75(4), 513-522.

Gross, C. 2007. Community perspectives of wind energy in Australia: The application of a justice and community fairness framework to increase social acceptance. Energy Policy, 35(5), 2727-2736. doi:10.1016/j.enpol.2006.12.013.

Gunningham, N., Kagan, R.A. \& Thornton, D. 2004. Social Licence and Environmental Protection: Why Businesses go Beyond Compliance. Law and Social Inquiry, 29, 307-341.

Hagendijk, R., and Kallerud, E. (2003). Changing Practices of Governance in Science and Technology in Europe: A Framework for Analysis. Science technology and governance in Europe (STAGE) discussion paper. www.stage-research.net.

Hindmarsh, R. \& Matthews, C. 2008. Deliberative Speak at the Turbine Face: Community Engagement, Wind Farms, and Renewable Energy Transitions, in Australia. Journal of Environmental Policy \& Planning, 10(3), 217-232. doi:10.1080/15239080802242662.

Howard-Grenville, J., Nash, J. and Coglianese, C. 2008. Constructing the License to Operate: Internal Factors and their Influence on Corporate Environmental Decisions. Law \& Policy, 30(1), 73-107.

IPCC. 2018. Summary for Policymakers of IPCC Special Report on Global Warming of $1.5^{\circ} \mathrm{C}$ approved by

governments [Press release]. http://www.ipcc.ch/pdf/session48/pr_181008_P48_spm_en.pdf. Jenkins, K., McCauley, D., Heffron, R., Stephan, H. \& Rehner, R. (2016). Energy justice: A conceptual review. Energy Research \& Social Science, 11, 174-182.

doi:10.1016/j.erss.2015.10.004.

Karami, S., Karami, E., Buys, L. and Drogemuller, R. 2017. System dynamic simulation: A new method in social impact assessment (SIA). Environmental Impact Assessment Review, 62, 25-34. doi:10.1016/j.eiar.2016.07.009.

Klare, M. T. (2011). The era of xtreme energy: Life after the age of oil - Dec 06, 2017. https://www.huffingtonpost.com/michael-t-klare/the-era-of-xtremeenergy_b_295304.html?guccounter=1\&guce_referrer_us=aHR0cHM6Ly93d3cuZ29vZ2xl LmNvbS8\&guce_referrer_cs=JhuaxrDW0weoMnj6h6h_EA.

Kleinman, D. L. (Ed.) 2000. Science, Technology and Democracy. Albany: State University of New York Press.

Kojo, M. and Richardson, P. 2014. The use of community benefits approaches in the siting of nuclear waste management facilities. Energy Strategy Reviews, 4, 34-42. doi:10.1016/j.esr.2014.06.004.

Kotsakis, A. 2012. The Regulation of the Technical, Environmental and Health Aspects of Current Exploratory Shale Gas Extraction in the United Kingdom: Initial Lessons for the Future of European Union Energy Policy. Review of European Community and International Environmental Law, 21(3), 282-290. 
Lebel, L., Anderies, J.M., Campbell, B., Folke, C., Hatfield-Dodds, S., Hughes, T.P. and Wilson, J. 2006. Governance and the Capacity to Manage Resilience in Regional SocialEcological Systems. Ecology and Society, 11(1), 19.

Lee, M., Armeni, C., Cendra, J. d., Chaytor, S., Lock, S., Maslin, M., . . Rydin, Y. 2012. Public Participation and Climate Change Infrastructure. Journal of Environmental Law, 25(1), 33-62. doi:10.1093/jel/eqs027.

Lin, A. 2016. Natural gas as a transition fuel: A bridge too far? 20/07/2016. https://thebulletin.org/2016/07/natural-gas-as-a-transition-fuel-a-bridge-too-far/.

MacCoun, R.J. 2005. Voice, Control, and Belonging: The Double-Edged Sword of Procedural Fairness. Annual Review of Law and Social Science, 1(1), 171-201. doi:10.1146/annurev.lawsocsci.1.041604.115958.

Miller, C.A. 2012. Energy Justice: Ensuring human dignity in the post carbon future. Cairo Review of Global Affairs, 5 (May), 46-59.

Miller, C.A., Iles, A. and Jones, C.F. 2013. The Social Dimensions of Energy Transitions. Science as Culture, 22(2), 135-148. doi:10.1080/09505431.2013.786989.

Naderpajouh, N., Mahdavi, A., Hastak, M. and Aldrich, D.P. 2014. Modeling Social Opposition to Infrastructure Development. Journal of Construction Engineering and Management, 140(8), 04014029. doi:10.1061/(asce)co.1943-7862.0000876.

NCVO. (2014). Big Local: the early years [Evaluation report]. http://localtrust.org.uk/assets/downloads/documents/Final_report_reduced.pdf.

Paydar, N.H., Clark, A., Rupp, J.A. and Graham, J.D. 2016. The effect of Pennsylvannia impact fee disbursements on local acceptance of unconventional gas development. Energy Research \& Social Science, 20, 31-44. doi.org/10.1016/j.erss.2016.04.007.

Plumer, B. 2014. "Obama says fracking can be a 'bridge' to a clean-energy future. It's not that simple." The Washington Monthly, 29 Jan 2014.

Rattle, I., van Alstine, J. and Baker, T. 2018. Shale gas development in England: a tale of two mineral planning authorities. In J. Whitton, Cotton, M., Brasier, K, and Charnley-Parry, I.M. (Eds.), Governing Shale Gas: Development, Citizen Participation and Decision Making in the US, Canada, Australia and Europe: Routledge.

Rogelj, J., den Elzen, M., Höhne, N., Fransen, T., Fekete, H., Winkler, H., . . Meinshausen, M. 2016. Paris Agreement climate proposals need a boost to keep warming well below $2{ }^{\circ} \mathrm{C}$. Nature, 534, 631. doi:10.1038/nature 18307.

https://www.nature.com/articles/nature18307\#supplementary-information.

Rootes, C. 2006. 8. Explaining the Outcomes of Campaigns against Waste Incinerators in England: Community, Ecology, Political Opportunities, and Policy Contexts. In A. M. McCright \& T. N. Clark (Eds.), In: Community and Ecology (Vol. 10, pp. 179-198): Emerald Publishing.

Rydin, Y., Lee, M. and Lock, S.J. 2015. Public Engagement in Decision-Making on Major Wind Energy Projects. Journal of Environmental Law, 27(1), 139-150. doi:10.1093/jel/eqv001.

Rydin, Y., Natarajan, L., Lee, M. and Lock, S. 2018. Do local economic interests matter when regulating nationally significant infrastructure? The case of renewable energy infrastructure projects. Local Economy: The Journal of the Local Economy Policy Unit, 33(3), 269-286. doi:10.1177/0269094218763000.

Shrader-Frechette, K. S. 2002. Environmental justice: creating equality, reclaiming democracy. Oxford: Oxford University Press.

Sierra, L.A., Yepes, V. and Pellicer, E. 2018. A review of multi-criteria assessment of the social sustainability of infrastructures. Journal of Cleaner Production, 187, 496-513. doi:10.1016/j.jclepro.2018.03.022. 
Stacey, K. and Pickard, J. 2013. Fracking should focus on 'desolate' northeast, says Lord Howell - July 30, 2013. https://www.ft.com/content/8faf3c78-f910-11e2-86e100144 feabdc0.

Soltani, A., Hewage, K., Reza, B. and Sadiq, R. 2015. Multiple stakeholders in multi-criteria decision-making in the context of Municipal Solid Waste Management: A review. Waste Manag, 35, 318-328. doi:10.1016/j.wasman.2014.09.010.

Sovacool, B.K. 2014. Cornucopia or curse? Reviewing the costs and benefits of shale gas hydraulic fracturing (fracking). Renewable and Sustainable Energy Reviews, 37, 249-264. doi:10.1016/j.rser.2014.04.068.

Sovacool, B.K. and Cooper, C.J. 2013. The Governance of Energy Megaprojects: Politics, Hubris and Energy Security. Cheltenham, UK: Edward Elgar Publishing Ltd.

Sovacool, B.K. and Dworkin, M.H. 2014. Global Energy Justice: Principles, Problems and Practices. Cambridge, UK: Cambridge University Press.

Sovacool, B.K., Sidorstov, R.V. and Jones, B.R. 2014. Energy Security, Equality, and Justice New York: Routledge.

Szolucha, A. 2018. Assessing risk from fracking in the UK and Poland: The limits of robust regulation and responsible development. In J. Whitton, Cotton, M., Brasier, K, and Charnley-Parry, I.M. (Eds.), Governing Shale Gas: Development, Citizen Participation and Decision Making in the US, Canada, Australia and Europe: Routledge.

Temper, L., del Bene, D. and Martinez-Alier, J. 2015. Mapping the frontiers and front lines of global environmental justice: the EJAtlas. Journal of Political Ecology, 22, 255-278.

Thibaut, J. and Walker, L. 1975. Procedural Justice. Hillsdale, NJ: Erlbaum.

Tillerson, R. 2013. Capitalizing on the coming era of energy abundance. Paper presented at the Address to the Texas Allience of Energy Producers, Houston, Texas, USA.

HM Treasury. 2016. Shale Wealth Fund: Consultation - August 2016. London: Crown Copyright.

https://assets.publishing.service.gov.uk/government/uploads/system/uploads/attachment_da ta/file/544241/shale_wealth_fund_final_pdf-a.pdf.

UCL. 2017. Evidence, Publics and Decision Making for Major Wind Infrastructure. https://www.ucl.ac.uk/nsips/pdfs/Final_Findings_Recommendations.

UKOOG (Producer). 2016. Community Engagement Charter: Oil and Gas from Unconventional Reservoirs - 17/01/16). http://www.ukoog.org.uk/community/charter.

Van de Graaf, T. 2017. Is OPEC dead? Oil exporters, the Paris agreement and the transition to a post-carbon world. Energy Research \& Social Science, 23, 182-188. doi:https://doi.org/10.1016/j.erss.2016.10.005.

van Stokkom, B. 2005. Deliberative group dynamics: power, status and affect in interactive policy making. Policy \& Politics, 33(3), 387-409. doi:10.1332/0305573054325701.

Visschers, V.H.M. and Siegrist, M. 2012. Fair play in energy policy decisions: Procedural fairness, outcome fairness and acceptance of the decision to rebuild nuclear power plants. Energy Policy, 46, 292-300. doi:https://doi.org/10.1016/j.enpol.2012.03.062.

Watt, N. (2014). Fracking in the UK: "We're going all out for shale," admits Cameron. https://www.theguardian.com/environment/2014/jan/13/shale-gas-fracking-cameron-allout.

Weijermars, R., Drijkoningen, G., Heimovaara, T.J., Rudolph, E.S.J., Weltje, G.J. and Wolf, K.H.A.A. 2011. Unconventional gas research initiative for clean energy transition in Europe. Journal of Natural Gas Science and Engineering, 3(2), 402-412. doi:10.1016/j.jngse.2011.04.002.

Whitton, J., Brasier, K., Charnley-Parry, I. and Cotton, M. 2017. Shale gas governance in the United Kingdom and the United States: Opportunities for public participation and the 
implications for social justice. Energy Research \& Social Science, 26, 11-22. doi:10.1016/j.erss.2017.01.015.

Whitton, J., Cotton, M., Brasier, K, and Charnley-Parry, I.M. 2018a. Governing Shale Gas: Development, Citizen Participation and Decision Making in the US, Canada, Australia and Europe: Routledge.

Whitton, J., Cotton, M., Brasier, K, and Charnley-Parry, I.M. 2018b. Introduction: Governing Shale Gas. In J. Whitton, Cotton, M., Brasier, K, and Charnley-Parry, I.M. (Ed.), Governing Shale Gas: Development, Citizen Participation and Decision Making in the US, Canada, Australia and Europe: Routledge.

Whitton, J., Parry, I. M., Akiyoshi, M. and Lawless, W. 2015. Conceptualizing a social sustainability framework for energy infrastructure decisions. Energy Research \& Social Science, 8, 127-138. doi:10.1016/j.erss.2015.05.010.

Wilsdon, J. and Willis, R. 2004. See-through Science: Why public engagement needs to move upstream. London: Demos.

Wüstenhagen, R., Wolsink, M. and Bürer, M.J. 2007. Social acceptance of renewable energy innovation: An introduction to the concept. Energy Policy, 35(5), 2683-2691. doi:https://doi.org/10.1016/j.enpol.2006.12.001.

Energy and Society Research Group, UCLan Energy, University of Central Lancashire, Preston. Lancashire. UK. PR1 2HE 